\title{
Mental Health Problems and Satisfaction with Amount of State Compensation for Intentional Violent Crime Victimization in The Netherlands
}

\author{
M. J. J. Kunst
}

Received: 12 August 2010/Accepted: 4 October 2011/Published online: 15 October 2011

(C) The Author(s) 2011. This article is published with open access at Springerlink.com

\begin{abstract}
The current study explored whether self-reported mental health problems among victims of violent crime $(n=151)$ affect their ratings of satisfaction with amount of financial compensation awarded by the Dutch state and vice versa. This topic is important to address, because satisfaction is often used as an indicator of quality of victim services. Relying on medical literature about satisfaction with compensation in patient populations, it was expected that satisfaction levels would be negatively associated with mental health problems. Mental health problems were assessed with the General Health Questionnaire. A threshold of 11/12 on this scale was used to differentiate between victims with and without probable mental health problems. In line with expectations, victims with probable mental health problems reported significantly lower levels of satisfaction than those without. Results remained unchanged after adjusting for potential confounding. Findings were discussed in light of study limitations and directions for future research.
\end{abstract}

Keywords Violence - Victimization - Mental health · State compensation · Victim satisfaction

\section{Introduction}

Victims of violent civilian trauma may suffer from a wide array of negative psychological and social adjustment problems, such as such as posttraumatic stress disorder (e.g., Orth et al. 2008), depression (e.g., Bargai et al. 2007), somatization,

M. J. J. Kunst $(\square)$

Faculty of Law, Institute for Criminal Law and Criminology,

Leiden University, Room C1.23, P.O. Box 9520, 2300 RA

Leiden, The Netherlands

e-mail: m.j.j.kunst@law.leidenuniv.nl hostility, generalized and phobic anxiety (Norris and Kaniasty 1994; Winkel 2009), eating disorders (Brady 2008), substance abuse (Vermeiren et al. 2003), insomnia (Krakow et al. 2001), and sexual dysfunctioning (Letourneau et al. 1996).

Many European countries, such as the Netherlands (see Wet Schadefonds Geweldsmisdrijven of 1975 and the European Convention on the Compensation of Victims of Violent Crimes of 1983), and the United States (see US Victims of Crime Act of 1984) provide victims of intentional violent crimes the opportunity to apply for financial compensation for these immaterial damages if they are not covered otherwise and are not due to culpability or unlawful behavior on the side of the victim. In spite of this, only a minority of eligible victims applies for state compensation (Alvidrez et al. 2008; McCormack 1991). Furthermore, while legal scholars have theorized about the rationale of state compensation for victims of crime (e.g., Ashworth 1986; Buck 2005; Willis 1984) and investigated differences between jurisdictions (e.g., Greer 1994; Groenhuijsen 2001; Villmow 1991), little empirical knowledge is available on how satisfied victims who do apply are with amount of compensation awarded and, more importantly, which factors are associated with satisfaction ratings. This topic is important to address, since lack of satisfaction may be seen as a kind of secondary victimization (i.e., perceived additional violation of legitimate rights or entitlements by the victim; see Montada 1994; Orth 2002; Orth and Maercker 2004). Despite a dearth of knowledge, a few studies have attempted to uncover correlates of victims' satisfaction with state compensation.

Victim Satisfaction with State Compensation: A Brief Overview of the Literature

The few studies that have been conducted on violent crime victims' satisfaction with compensation from the state 
suggest that satisfaction ratings are associated with white female sex and administrative inconvenience, such quickness of claim resolution, and perceptions of adequate reward (Elias 1984; Newmark et al. 2003; Newmark 2004). The latter findings are in line with the objective of victim compensation schemes to express society's solidarity with the victim. To fulfill this purpose, compensation should be "subjectively felt by the victim to be adequate" (Wright 1998, p. 89).

Since satisfaction represents a "(...) general evaluation or feeling of favorableness toward the object in question (...)" (Fishbein and Azjen 1975, p. 11), victims' satisfaction levels may be distorted by affective states (see also Prince 2005). To date, one study has addressed this topic. Orth (2004) investigated whether satisfaction with level of compensation for material damages and pain and suffering (i.e., immaterial damage) was associated with feelings of revenge. Revenge is an affective state in response to harm intentionally caused by others (Collens 1998). Mean satisfaction level in this study was rather low given the scale width on which satisfaction items had to be rated. Both univariate and multivariate analyses yielded significant negative associations between satisfaction with compensation level and current feelings of revenge. Notwithstanding these results, one might speculate that the contribution of affective states to low satisfaction ratings is particularly strong if they reflect the presence of mental health problems. After all, several studies suggest that negative affect is related to increased symptoms of psychological distress (e.g. Crawford and Henry 2004). Preliminary support for this contention is provided by studies on satisfaction with services conducted in medical patient populations.

\section{Mental Health and Satisfaction with Services in Medical Literature}

Generally stated, medical research on the association between mental health and satisfaction with services is mainly cross-sectional in nature and has relied on either of two statistical approaches. One set of studies entered mental health as the dependent variable and satisfaction with services as the independent variable into statistical analyses. Many of these studies suggest that satisfaction with services is associated with adverse mental health status above and beyond background characteristics (e.g., Carlson and Gabriel 2001; Garland et al. 2003; Gigantesco et al. 2002). Reversely, a number of other studies entered mental health as the independent variable and satisfaction with medical services as the dependent variable into statistical analyses and found that mental health problems were associated negatively with satisfaction with services above and beyond background characteristics (e.g., Chen et al. 2006; Greenberg and Rosenheck 2004; Hoff et al. 1999; Rosenheck et al. 1997; Ruggeri et al. 2003; Turchik et al. 2010; for an early meta-analysis see Lehman and Zastowny 1983). In line with Switzer et al. (1999), these results may be interpreted to suggest that satisfaction serves as an important indicator of unidentified or unsolved medical or psychological problems. This notion is also relevant with respect to violent crime victims. This group often fails to seek help for psychological problems resulting from the act of victimization (Logan et al. 2005), but may nevertheless seek compensation from the state. Dissatisfaction with state compensation might thus be speculated to indicate that the victim involved suffers from underlying mental health problems unknown to or neglected by victim services.

\section{The Current Study}

Given the aforementioned, the purpose of the current study was to explore whether mental health problems and satisfaction with amount of state compensation for intentional violent crime victimization were interrelated. If so, satisfaction may not be an adequate indicator for policy makers to evaluate services provided by victim compensation schemes and should merely be conceived as an indicator of undetected mental health problems. Relying on medical literature, it was expected that mental health problems and satisfaction with compensation would be negatively correlated.

\section{Methods}

\section{Procedure}

This study used wave 2 data from a larger study into the psychosocial consequences of violent victimization (see also Kunst et al. 2010). Participants were recruited among victims who had applied for compensation with the Dutch Victim Compensation Fund (DVCF) in 2006. Eligible for participation were those who: (1) did not have missing file data on age, gender, and time since victimization (i.e., time elapse in years between victimization and study entry $)^{1} ;(2)$ were $\geq 18$ years old at time of study entry; (3) indicated they had been awarded compensation from the fund, and (4) had provided informed consent to participate in the current study. Those who had agreed to participate were invited to complete an Internet survey on satisfaction with compensation, mental health status, feelings of revenge,

\footnotetext{
${ }^{1}$ Missing file data on these variables indicated that the victim involved had failed to return the application form after an initial request for sending such a form.
} 
and victim service utilization. The latter two variables were important to assess to enable adjustment for potential confounding in statistical analyses. Revenge is the only (non-pathological) affective state which has been identified as a correlate of victims' levels of satisfaction with state compensation in previous research (see Orth 2004) and mental health (e.g., Orth et al. 2006), while history of service utilization in victims eligible for state compensation appears to be an important associate of mental health (see for example New and Berliner 2000). Participants who did not have access to the World Wide Web or preferred to fill out the questionnaire on paper could request for a hardcopy version. Remaining background information (age, gender, time since victimization, level of compensation for pain and suffering $(0=€ 0$ and $9=€ 9,100)$, number of claimed material damage categories, and type of violence $^{2}$ ) for all victims who had applied for compensation in 2006 was retrieved from the DVCF's electronic files. The study was approved by the DVCF Committee.

\section{Participants}

Two hundred and thirty-five (36.7\%) of those who had agreed to participate responded to the request for participation. One hundred and fifty-one respondents fulfilled inclusion criteria. Victims included in the study were more often female $(97 / 151,64.2 \%$ vs. $1,737 / 3,570,48.7 \%$, $P<.001$ ), had been victimized earlier (mean time since victimization for participants in years was 5.66 $(S D=5.02)$ vs. $M=4.75(S D=3.53)$ for non-participants, $P<.01$ ), had received higher levels of compensation for pain and suffering $(M=2.6, S D=1.8$ vs. $M=2.0, S D=1.8, P<.001)$, had sought compensation for more categories of material damages $(M=2.71$, $S D=2.15$ vs. $M=2.21, S D=2.17, P<.001)$, and had experienced sexual violence more often than non-participants $(29 / 151,19.2 \%$ vs. $441 / 3,570,12.4 \%, P<.025)$. No differences were observed for age $(M=41.2, S D=14.5$ vs. $M=39.5, S D=15.6)$, severe physical assault $(12 / 151$, $7.9 \%$ vs. $403 / 3,570,11.3 \%)$, moderate physical assault $(643 / 151,28.5 \%$ vs. $1,205 / 3,570,33.8 \%)$, and theft with violence $(43 / 151,28.5 \%$ vs. $896 / 3,570,25.1 \%)$.

\footnotetext{
$\overline{2}$ The DCVF categorizes type of violence according to their legal classification used in the Dutch Penal Code (DPC). To enable statistical testing, the number of different categories was reduced from 30 to 5: sexual violence, severe physical assault, moderate physical assault, theft with violence, and other (cf. Kunst et al. 2010). Severe and moderate physical assault and theft with violence corresponded to the original file categorization. Sexual violence included all individuals that had experienced an offence falling under Book 2, Title XIV of the DPC. The remainder of the sample is a mixture of offences that were too low in number to form a category of their own. This group served as reference category.
}

Measures

\section{Satisfaction with Compensation}

Two items were used to measure satisfaction with compensation: one for satisfaction with compensation for material damages ("Are you satisfied with amount of compensation rewarded for material damages?") and one for satisfaction with compensation for pain and suffering ("Are you satisfied with amount of compensation rewarded for pain and suffering?"). Items were derived from Orth (2004) and had to be rated on a 7-point Likert scale $(0=$ not at all, $6=$ sufficient $)$. Prior to statistical analyses, an average compensation score was calculated by summing item scores and dividing its sum by the number of awarded compensation types ( 1 or 2 ). Internal consistency reliability of the compensation scale among those who had received both compensation for material damages and pain and suffering $(n=71)$ was Cronbach's $\alpha=.74$.

\section{Mental Health Status}

The 12-item General Health Questionnaire (GHQ-12) was administered to approximate participants' current mental health status. The GHQ-12 is an excellent screening instrument (Goldberg et al. 1997). Items had to be rated on a 4-point Likert scale $(0=$ not at all, $1=$ same as usual, $2=$ rather more than usual, and $3=$ much more than usual). An example item is "Have you lost much sleep lately/ recently?" A threshold of 11/12 was used to differentiate between victims with and without probable mental health problems (cf. Goldberg et al. 1997), with subjects scoring above this cut off qualifying for probable mental health problems. "Probable" does not indicate that such persons suffer from psychiatric illness, but suggests that they require further attention (Jackson 2007). Internal consistency reliability of the GHQ-12 was Cronbach's $\alpha=.81$.

\section{Feelings of Revenge}

A Dutch translation of the 3-item revenge scale developed by Orth (2003) was administered to assess feelings of revenge during the past 4 weeks. This instrument is similar to the revenge scale used by Orth (2004). An example item is "How often did you think about doing something to the perpetrator, without actually doing it?" Answers had to be rated on a 6-point Likert scale $(0=$ never, $5=$ very often $)$. Internal consistency reliability of the revenge scale was Cronbach's $\alpha=.97$.

\section{Victim Service Utilization}

One self-developed item was used to check whether participants had received victim support ("no", "yes, by a 
Victim Support Netherlands (VSN) volunteer", “yes, by a social worker", "yes, by a clinical psychologist/psychiatrist", "yes, by another aid administrator"). Those who had received help were coded as yes $=1$ and no $=0$.

\section{Statistical Analyses}

To describe the study sample, means and standard deviations or frequencies and percentages were computed for all background variables. Independent $t$ tests and Chi square analyses, as appropriate, were conducted to examine differences in satisfaction with compensation and background variables between participants with and without probable mental health problems. Next, a hierarchical linear regression analysis was conducted to test whether an observed association between probable mental health problems (as independent variable) and satisfaction with compensation (as dependent variable) would still reach significance after adjusting for feelings of revenge, history of service utilization, and other background variables. In addition, hierarchical logistic regression analysis was used to see whether satisfaction with compensation (as independent variable) would remain significantly associated with probable mental health problems (as dependent variable) in a multivariate model. In both regression analyses, the independent variable of interest was entered on the first step and background variables on the second step. Prior to statistical analyses, data were checked for underlying assumptions. The alpha level was set at .05 in all statistical tests. All statistical analyses were performed using the software package SPSS 16.0 for Windows (SPSS Inc., Chicago, Illinois).

\section{Results}

\section{Descriptive Statistics}

Descriptive statistics are summarized in Table 1. One hundred and seventeen (74.5\%) participants fulfilled the GHQ-12 cut off score for probable mental health problems. Subjects in this group had experienced sexual violence less often than those scoring below the cut off $(18 / 117,15.4 \%$ vs. $11 / 34,32.4 \%), \chi^{2}(1, N=151)=4.88, P<.05$. No differences on any of the remaining background variables were observed. As expected, mean level of satisfaction with compensation for participants with probable mental health problems $(M=3.8, S D=2.0)$ was significantly lower than for those without such problems $(M=4.6$, $S D=1.3), t(149)=2.9, P<.01)$.

\section{Regression Analyses}

Linear regression analysis yielded a significant negative association between probable mental health problems and satisfaction with compensation, even after adjusting for background variables. None of the background variables correlated significantly with satisfaction in this analysis

Table 1 Sample characteristics by mental health status

\begin{tabular}{|c|c|c|c|c|}
\hline & \multicolumn{4}{|c|}{ Mental health status } \\
\hline & \multicolumn{2}{|c|}{ High $(n=117)$} & \multicolumn{2}{|c|}{ Low $(n=34)$} \\
\hline & $M$ & $S D$ & $M$ & $S D$ \\
\hline Age & 41.0 & 13.6 & 42.3 & 17.5 \\
\hline Time since victimization in years & 5.8 & 5.4 & 5.1 & 3.5 \\
\hline Number of claimed (material) damage categories & 2.7 & 2.2 & 2.8 & 2.1 \\
\hline Level of compensation for pain and suffering & 2.5 & 1.7 & 2.9 & 1.9 \\
\hline \multirow[t]{2}{*}{ Feelings of revenge } & 5.8 & 5.5 & 3.7 & 5.5 \\
\hline & $n$ & $\%$ & $n$ & $\%$ \\
\hline Gender (male) & 40 & 34.2 & 14 & 41.2 \\
\hline Sexual violence & 18 & 15.4 & 11 & $32.4 *$ \\
\hline Physical violence (severe) & 9 & 7.7 & 3 & 8.8 \\
\hline Physical violence (moderate) & 36 & 30.8 & 7 & 20.6 \\
\hline Theft with violence & 32 & 27.4 & 11 & 32.4 \\
\hline Victim service utilization & 98 & 83.8 & 29 & 85.3 \\
\hline
\end{tabular}

Note that $63(41.7 \%)$ victims (48 in the low and 15 in the high mental health group) received support from a VSN volunteer, while only 19 $(12.6 \%)$ victims (14 in the low and 5 in the high mental health group) received professional help (i.e., by a clinical psychologist or psychiatrist)

$* P<.05$ 
Table 2 Linear regression model predicting the variance in satisfaction with state compensation $(n=151)$

\begin{tabular}{lcc}
\hline Variables & $\beta$ & $\Delta R^{2}$ \\
\hline Step 1 & & \\
Probable mental health problems & $-.19^{* *}$ & $.035^{* *}$ \\
Step 2 & & \\
Probable mental health problems & $-.18^{*}$ & .067 \\
Gender (male) & -.03 & \\
Age & .01 & \\
Time since victimization in years & .14 & \\
Number of claimed (material) damage categories & -.09 & \\
Level of compensation for pain and suffering & .09 & \\
Sexual violence & -.05 & \\
Physical assault (severe) & -.07 & \\
Physical assault (moderate) & -.13 & \\
Theft with violence & .00 & \\
Feelings of revenge & -.04 & \\
Victim service utilization & .05 & \\
\hline
\end{tabular}

** $P<.025 ; * P<.05$

(see Table 2). The final model explained slightly more than $10 \%$ of the variance in satisfaction with state compensation. Logistic regression produced similar results. Satisfaction with state compensation was significantly and negatively associated with probable mental health problems. Inspection of odds ratios suggested that the odds for probable mental health problems would decrease with almost $25 \%$ with each unit increase in satisfaction with state compensation. Sexual violence was the only background variable which was significantly and negatively associated with probable mental health problems. Odds ratios indicated that victims of sexual violence were almost twice as less likely to suffer from probable mental health problems than not compared to those with histories of nonsexual violent victimization. The final model explained between 15 and $22.8 \%$ of the pseudo variance in probable mental health problems (see Table 3 ).

\section{Discussion}

The present study explored the association between mental health problems and satisfaction with state compensation for intentional violent crime victimization. Relying on studies about the association between mental health and satisfaction with services in medical patient populations, mental health was predicted to influence satisfaction scores and vice versa. In line with expectations and previous studies (e.g., Hoff et al. 1999), results indicated that victims with high levels of self-reported mental problems reported lower levels of satisfaction with amount of
Table 3 Logistic regression model predicting the odds of probable mental health problems $(n=151)$

\begin{tabular}{|c|c|c|}
\hline Variables & $\begin{array}{l}\text { Step } 1 \\
\text { OR }(95 \% \text { CI })\end{array}$ & $\begin{array}{l}\text { Step } 2 \\
\text { OR }(95 \% \mathrm{CI})\end{array}$ \\
\hline $\begin{array}{l}\text { Satisfaction with state } \\
\text { compensation }\end{array}$ & $.76(.60-.97)^{* *}$ & $.76(.58-.98)^{*}$ \\
\hline Gender (male) & & $.42(.15-1.21)$ \\
\hline Age & & $.98(.95-1.01)$ \\
\hline $\begin{array}{l}\text { Time since victimization in } \\
\text { years }\end{array}$ & & $1.10(.96-1.27)$ \\
\hline $\begin{array}{l}\text { Number of claimed (material) } \\
\text { damage categories }\end{array}$ & & $.93(.74-1.17)$ \\
\hline $\begin{array}{l}\text { Level of compensation } \\
\text { for pain and suffering }\end{array}$ & & $1.09(.82-1.44)$ \\
\hline Sexual violence & & $.06(.01-.41)^{* * *}$ \\
\hline Physical assault (severe) & & $.47(.05-4.19)$ \\
\hline Physical assault (moderate) & & $.76(.12-4.74)$ \\
\hline Theft with violence & & $.31(.05-1.71)$ \\
\hline Feelings of revenge & & $1.09(1.00-1.18)$ \\
\hline Victim support & & $.92(.25-3.36)$ \\
\hline$\chi^{2}$ (change), df & $5.79,1^{* *}$ & $18.67^{\dagger}$ \\
\hline Cox and Snell $R^{2}$ & .038 & .15 \\
\hline Nagelkerke $R^{2}$ & .057 & .23 \\
\hline $\begin{array}{l}\text { Hosmer-Lemeshow } \\
\text { fit }\left(\chi^{2}, P\right)\end{array}$ & $3.69, .59$ & $7.11,53$ \\
\hline
\end{tabular}

compensation than those with low levels. The negative association between mental health problems and satisfaction levels remained significant in multivariate analyses and irrespective of whether satisfaction or mental health scores served as outcome variable.

Findings may be interpreted to argue that caution should be taken when estimating victims' levels of satisfaction with amount of financial compensation by the state. Apparently, satisfaction scores do not necessarily reflect adequacy in terms of meeting victims' needs for recognition through monetary reward and may also be interpreted to indicate which victims (still) suffer from psychological distress, either due to or not due to the act of victimization. Lawyers and other professionals involved in the evaluation of victims' requests for compensation may play an important role in advising such victims to seek help. Unfortunately, to date, victim compensation funds have solely been pictured as targets of referral (e.g., Fritsch et al. 2004) and not as a source of referral. Significant in this respect is that a contract concluded between the DVCF and VSN in 2006 aims to improve referral to the fund by VSN volunteers, but not the other way around. Furthermore, it does not regard referral to other mental health services. Inclusion of a short mental health screener in DVCF 
application forms may ensure that victims with mental health problems still get the help they need and failed to ask for themselves (cf. Kunst et al. 2010). An example of such a screening instrument is the Trauma Screening Questionnaire (TSQ; Brewin et al. 2002). Dekkers et al. (2010) have recently shown that the TSQ is suitable for screening purposes. Relying on the collected data, distressed victims should, however, not be simply referred to VSN. After all, the majority of study participants had received support from a VSN volunteer (see legend Table 1). Presumably, those who apply for compensation with the fund and still suffer from high levels of distress at the start of the application procedure require a level of intervention that surpasses standard victim support.

When considering the study's results alternative interpretations need consideration as well. Another explanation for the differences in satisfaction between victims with and without probable mental health problems is that the former were truly less satisfied with amount of financial reward than the latter. For example, one might speculate that victims suffering from mental health problems spent more money on overcoming the aftermath of victimization than those without such problems. Particularly if victims' losses in the probable mental health problems group exceeded the maximum amount of compensation allowed to be rewarded by the fund more often than losses in the other group, differences in level of satisfaction between the two groups may have reflected real variation in discontent. Furthermore, due to its written nature, the application procedure may have neglected victims' immaterial needs. It might be argued that those in the probable mental health problems group needed an opportunity to comment upon the submission of the claim. If so, this may have biased their satisfaction scores.

The present study was not without its limitations. First, findings were cross-sectional in nature. Cause and effect could therefore not be determined. Second, the study relied on self-report measures to assess mental health problems. Self-report assessments are less reliable than interviewbased assessments. Third, study data did not allow adjustment for victims' ethnic background. As mentioned in the "Introduction" section, previous studies suggest that this variable may be an important confounder in satisfaction research among victims of violent crime applying for state compensation (Newmark et al. 2003; Newmark 2004). Fourth, the psychometric properties of our measures of satisfaction with compensation and feelings of revenge are unknown. Fifth, our sample may have lacked representativeness for two reasons: (1) response rate was rather low and (2) non-response analyses indicated that participants differed from non-participants in several respects. However, many of these differences were likely to be due to differences in sample size. Sixth, effect sizes in this study were rather low. This indicates that many factors determining satisfaction and mental health were not measured. For example, this study did not assess perceived procedural (i.e., victims' appraisals of the fairness of the procedure; see Lind and Taylor 1988; Thibaut and Walker 1975; Tyler 1990) and interactional justice (i.e., victims' appraisals of being treated with respect and politeness; see Bies and Moag 1986; Lind and Taylor 1988). Given the purely written nature of the application procedure, this was not deemed appropriate. After all, such procedures do not allow victims to tell their story in person to the decision maker-a key source of differences in appraisals of procedural and interactional justice. This cannot refute, however, that the lack of opportunity to do so may have influenced victims' satisfaction ratings.

Despite the study's limitations, it was worthwhile for several reasons. Most important, it was the first study to examine the relationship between mental health problems and satisfaction with amount of compensation for intentional violent crime victimization. A methodological strength was that it took into account the potentially confounding effects of self-reported feelings of revenge and victim service utilization and other claimant characteristics. Another strong feature is that it largely relied on objective file data when collecting background information.

In addition to overcoming this study's limitations, future studies might consider the investigation of positive outcomes of violent crime victimization, such as experiences of posttraumatic growth (PTG), in relation to satisfaction with amount of reward. Zoellner and Maercker (2006) defined PTG as "the subjective experience of positive psychological change reported by an individual as result of the struggle with trauma" (p. 628). Individuals who have experienced a highly traumatic event need to accommodate pretrauma schema's about the world, self, and others (Janoff-Bulman 1992) and thereby tend to find meaning in the event itself (Taylor 1983). The outcome of this mean-making process may result in PTG (Joseph and Linley 2005, 2006; Tedeschi and Calhoun 1995, 2004). It would be particularly interesting to test whether satisfaction with compensation facilitates PTG and the other way around and whether PTG or underlying resiliency factors moderate the association between mental health problems and satisfaction with compensation.

Acknowledgments The author thanks the Dutch Victim Compensation Fund for its support with the data collection.

Open Access This article is distributed under the terms of the Creative Commons Attribution Noncommercial License which permits any noncommercial use, distribution, and reproduction in any medium, provided the original author(s) and source are credited. 


\section{References}

Alvidrez, J., Shumway, M., Boccellari, A., Green, J. D., Kelly, V., \& Merill, G. (2008). Reduction of state victim compensation disparities in disadvantaged crime through active outreach and assistance: A randomized trial. American Journal of Public Health, 98, 882-888.

Ashworth, A. (1986). Punishment and compensation: Victims, offenders and the state. Oxford Journal of Legal Studies, 6, $86-122$.

Bargai, N., Ben-Shakhar, G., \& Shalev, A. Y. (2007). Posttraumatic stress disorder and depression in battered women: The mediating role of learned helplessness. Journal of Family Violence, 22, 267-275.

Bies, R. J., \& Moag, J. S. (1986). Interactional justice: Communication criteria of fairness. In R. J. Lewicki, B. H. Sheppard, \& M. H. Bazerman (Eds.), Research on negotiation in organizations (pp. 43-55). Greenwich, CT: JAI Press.

Brady, S. S. (2008). Lifetime family violence exposure is associated with current symptoms of eating disorders among both young men and women. Journal of Traumatic Stress, 21, 347-351.

Brewin, C. R., Rose, S., Andrews, B., Green, J., Tata, P., McEvedy, C., et al. (2002). Brief screening instrument for post-traumatic stress disorder. The British Journal of Psychiatry, 181, 158-162.

Buck, K. (2005). State compensation to crime victims and the principle of social solidarity. Can theoretical analysis contribute to a future European framework? European Journal of Crime, Criminal Law and Criminal Justice, 13, 148-178.

Carlson, M. J., \& Gabriel, R. M. (2001). Patient satisfaction, use of services, and one-year outcomes in publicly funded substance abuse treatment. Psychiatric Services, 52, 1230-1236.

Chen, H., Coakley, E. H., Cheal, K., Maxwell, J., Costantino, G., Krahn, D. D., et al. (2006). Satisfaction with mental health services in older primary care patients. American Journal of Geriatric Psychiatry, 14, 371-379.

Collens, P. (1998). The value of revenge in analytic theory and practice. British Journal of Psychotherapy, 14, 502-512.

Crawford, J. R., \& Henry, J. D. (2004). The Positive and Negative Affect Schedule (PANAS): Construct validity, measurement properties and normative data in a large non-clinical sample. British Journal of Clinical Psychology, 43, 245-265.

Dekkers, A., Olff, M., \& Näring, G. (2010). Identifying persons at risk for PTSD after trauma with TSQ in The Netherlands. Community Mental Health Journal, 46, 20-25.

Elias, R. (1984). Alienating the victim: Compensation and victim attitudes. Journal of Social Issues, 40, 103-116.

Fishbein, M., \& Azjen, I. (1975). Belief, attitude, intention and behavior: An introduction to theory and research. Reading, MA: Addison-Wesley.

Fritsch, E. J., Caeti, T. J., Tobolowsky, P. M., \& Taylor, R. W. (2004). Police referrals of crime victims to compensation sources: An empirical analysis of attitudinal and structural impediments. Police Quarterly, 7, 372-393.

Garland, A. F., Aarons, G. A., Hawley, K. M., \& Hough, R. L. (2003). Relationship of youth satisfaction with mental health services and changes in symptoms and functioning. Psychiatric Services, $54,1544-1546$.

Gigantesco, A., Picardi, A., Chiaia, E., Balbi, A., \& Morosini, P. (2002). Patients' and relatives' satisfaction with psychiatric services in a large catchment area in Rome. European Psychiatry, 17, 139-147.

Goldberg, D. P., Gater, R., Sartorius, N., Ustun, T. B., Piccinelli, M., Gureje, O., et al. (1997). The validity of two versions of the GHQ in the WHO study of mental illness in general health care. Psychological Medicine, 27, 191-197.
Greenberg, G. A., \& Rosenheck, R. A. (2004). Consumer satisfaction with inpatient mental health treatment in the Department of Veterans Affairs. Administration and Policy in Mental Health and Mental Health Services Research, 31, 465-481.

Greer, D. S. (1994). A Transatlantic perspective on the compensation of crime victims in the United States. Journal of Criminal Law \& Criminology, 85, pp 333-401.

Groenhuijsen, M. S. (2001). Public damage funds. European Developments and some comparative observations. In E. Fattah \& S. Parmentier (Eds.), Victim policies and criminal justice on the road to restorative justice-Essays in honour of Tony Peters (pp. 83-97). Belgium, Leuven: Leuven University Press.

Hoff, R. A., Rosenheck, R. A., Meterko, M., \& Wilson, N. J. (1999). Mental illness as a predictor of satisfaction with inpatient care at Veterans Affairs hospitals. Psychiatric Services, 50, 680-685.

Jackson, C. (2007). The general health questionnaire. Occupational Medicine, 57, 79.

Janoff-Bulman, R. (1992). Shattered assumptions: Towards a new psychology of trauma. New York: The Free Press.

Joseph, S., \& Linley, P. A. (2005). Positive adjustment to threatening events: An organismic valuing theory of growth through adversity. Review of General Psychology, 9, 262-280.

Joseph, S., \& Linley, P. A. (2006). Growth following adversity: Theoretical perspectives and implications for clinical practice. Clinical Psychology Review, 26, 1041-1053.

Krakow, B., Melendrez, D., Pedersen, B., Johnston, L., Hollifield, M., Germain, A., et al. (2001). Complex insomnia: Insomnia and sleep-disordered breathing in a consecutive series of crime victims with nightmares and PTSD. Biological Psychiatry, 49, 948-953.

Kunst, M. J. J., Winkel, F. W., \& Bogaerts, S. (2010). Prevalence and predictors of posttraumatic stress disorder among victims of violence applying for state compensation. Journal of Interpersonal Violence, 25, 1631-1654.

Lehman, A. F., \& Zastowny, T. R. (1983). Patient satisfaction with mental health services: A meta-analysis to establish norms. Evaluation and Program Planning, 6, 265-274.

Letourneau, E. J., Resnick, H. S., Kilpatrick, D. G., Saunders, B. E., \& Best, C. L. (1996). Comorbidity of sexual problems and posttraumatic stress disorder in female crime victims. Behavior Therapy, 27, 321-336.

Lind, E. A., \& Taylor, T. R. (1988). The social psychology of procedural justice. New York: Plenum.

Logan, T. K., Evans, L., Stevenson, E., \& Jordan, C. E. (2005). Barriers to services for rural and urban survivors of rape. Journal of Interpersonal Violence, 20, 591-616.

McCormack, R. J. (1991). Compensating victims of violent crime. Justice Quarterly, 8, 329-346.

Montada, L. (1994). Injustice in harm and loss. Social Justice Research, 7, 5-28.

New, M., \& Berliner, L. (2000). Mental health service utilization by victims of crime. Journal of Traumatic Stress, 13, 693-707.

Newmark, L. C. (2004). Crime victims' needs and VOCA funded services: findings and recommendations from two national studies. Alexandria, VA: National Institute of Justice. Retrieved July 20, 2010, from http://www.ncjrs.gov/pdffiles1/nij/grants/ 214263.pdf.

Newmark, L., Bonderman, J., Smith, B., \& Liner, B. (2003). The national evaluation of state Victims of Crime Act compensation and assistance programs: trends and strategies for the future. Washington, DC: Urban Institute. Retrieved July 20, 2010, from http://www.urban.org/UploadedPDF/410142_VOCA_report.pdf.

Norris, F. H., \& Kaniasty, K. (1994). Psychological distress following criminal victimization in the general population: Cross-sectional, longitudinal, and prospective analyses. Journal of Consulting and Clinical Psychology, 62, 111-123. 
Orth, U. (2002). Secondary victimisation of crime victims by criminal proceedings. Social Justice Research, 15, 313-325.

Orth, U. (2003). Punishment goals of crime victims. Law and Human Behavior, 27, 173-186.

Orth, U. (2004). Does perpetrator punishment satisfy victims' feelings of revenge? Aggressive Behavior, 30, 62-70.

Orth, U., Cahill, S. P., Foa, E. B., \& Maercker, A. (2008). Anger and posttraumatic stress disorder symptoms in crime victims: A longitudinal analysis. Journal of Consulting and Clinical Psychology, 76, 208-218.

Orth, U., \& Maercker, A. (2004). Do Trials of perpetrators retraumatize crime victims? Journal of Interpersonal Violence, $19,212-227$.

Orth, U., Montada, L., \& Maercker, A. (2006). Feelings of revenge, retaliation motive, and posttraumatic stress reactions in crime victims. Journal of Interpersonal Violence, 21, 229-243.

Prince, J. D. (2005). Life contentment and mental health care satisfaction. Research on Social Work Practice, 15, 564-567.

Rosenheck, R., Wilson, N., \& Meterko, M. (1997). Influence of patient and hospital factors on consumer satisfaction with inpatient mental health treatment. Psychiatric Services, 48, 1553-1561.

Ruggeri, M., Lasalvia, A., Bisoffi, G., Thornicroft, G., VazquezBarquero, J. L., Becker, T., et al. (2003). Satisfaction with mental health services among people with Schizophrenia in five European sites: Results from the EPSILON study. Schizophrenia Bulletin, 29, 229-245.

Switzer, G. E., Dew, M. A., Thompson, K., Goycoolea, J. M., Derricott, T., \& Mullins, S. D. (1999). Posttraumatic stress disorder and service utilization among urban mental health center clients. Journal of Traumatic Stress, 12, 25-39.

Taylor, S. E. (1983). Adjustment to threatening events: A theory of cognitive adaptation. American Psychologist, 38, 1161-1173.

Tedeschi, R. G., \& Calhoun, L. G. (1995). Trauma and transformation: Growing in the aftermath of suffering. Thousand Oaks, CA: Sage Publications.
Tedeschi, R. G., \& Calhoun, L. G. (2004). Posttraumatic growth: Conceptual foundations and empirical evidence. Psychological Inquiry, 15, 1-18.

Thibaut, J., \& Walker, L. (1975). Procedural justice: A psychological analysis. Hillsdale, NJ: Lawrence Erlbaum Associates.

Turchik, J. A., Karpenko, V., Ogles, B. M., Demireva, P., \& Probst, D. R. (2010). Parent and adolescent satisfaction with mental health services: Does it relate to youth diagnosis, age, gender, or treatment outcome? Community Mental Health Journal, 46, 282-288.

Tyler, T. R. (1990). Why people obey the law. New Haven, CT: Yale University Press.

Vermeiren, R., Schwab-Stone, M., Deboutte, D., Leckman, P. E., \& Ruchkin, V. (2003). Violence exposure and substance use in adolescents: Findings from three countries. Pediatrics, 111, $535-540$.

Villmow, B. (1991). Victim compensation in some Western countries. In K. Sessar \& H.-J. Kerner (Eds.), Developments in crime and control research-German studies on victims, offenders, and the public (pp. 66-86). New York, NY: Springer.

Willis, B. L. (1984). State compensation of victims of violent crimes: The Council of Europe Convention of 1983. Virginia Journal of International Law, 25, 211-248.

Winkel, F. W. (2009). Fear of crime (type A) revisited: Predicting panic disorder and persistent panic and fear symptoms following criminal victimization. International Perspectives in Victimology, 4, 35-42.

Wright, M. (1998). Why should victims be compensated? In E. Fattah \& T. Peters (Eds.), Support for crime victims in a comparative perspective- a collection of essays dedicated to the memory of Prof. F. McFlintock (pp. 83-94). Belgium, Leuven: Leuven University Press.

Zoellner, T., \& Maercker, A. (2006). Posttraumatic growth in clinical psychology: A critical review and introduction of a two component model. Clinical Psychology Review, 26, 626-653. 